\title{
Sarcoidose ovárica e pulmonar - um diagnóstico a considerar
}

\author{
Pulmonary and ovarian sarcoidosis - a diagnosis to consider
}

\author{
Susana Barbosa, Paula Felgueiras, Diana Guerra, Alfredo Pinto \\ Serviço de Medicina 1, Hospital de Santa Luzia, Unidade Local de Saúde do Alto Minho
}

\begin{abstract}
Resumo
A sarcoidose é uma doença granulomatosa sistémica de etiologia desconhecida. A tuberculose pode preceder, coexistir com a sarcoidose ou, menos frequentemente, trata-se de uma doença oportunista nos doentes com sarcoidose sob corticoterapia. Os autores apresentam o caso de uma doente de 60 anos que iniciou queixas de tosse seca, febre e sudorese noturna. Posteriormente aparecimento de massa pélvica, tendo sido colocada a hipótese de neoplasia do ovário e submetida a histerectomia e anexectomia bilateral. Exame histológico revelou estruturas granulomatosas circunscritas, constituídos por histiócitos, sem evidência de necrose caseosa. Exame cultural do líquido ascítico isolamento de Mycobacterium tuberculosis. TC de tórax revelou múltiplas adenomegalias mediastínicas e espessamento difuso do interstício, com um padrão misto reticular/nodular. Cumpriu 9 meses de anti-tuberculosos. Analiticamente elevação da enzima de conversão da angiotensina. Efetuada biópsia pulmonar transtorácica, cuja histologia revelou septos interalveolares espessados por fibrose e infiltrado de macrófagos epitelióides, com granulomas não caseosos, compatíveis com o diagnóstico de sarcoidose.
\end{abstract}

Palavras-chave: sarcoidose pulmonar; sarcoidose ovárica; tuberculose.

\section{Introdução}

A sarcoidose é uma doença granulomatosa sistémica de etiologia desconhecida. ${ }^{1-6}$ Afeta pessoas em todo 0 mundo, sobretudo jovens adultos, com idade inferior a 50 anos. ${ }^{1} \mathrm{~A}$ prevalência estimada no mundo é de 16, 5/100000 nos homens e 19/100000 nas mulheres. ${ }^{2}$ Qualquer órgão pode ser atingido, sendo os pulmões e o sistema linfático os órgãos preferencialmente afectados. ${ }^{1,2} \mathrm{~A}$ etiologia é desconhecida mas aceita-se que a doença seja consequência de uma resposta imunológica crónica, devido à interação de dois fatores, suscetibilidade genética e estímulos ambientais ou infeciosos. ${ }^{1,2,5,6}$ A evolução e a gravidade da doença é muito variável, ocorrendo resolução espontânea dentro de 12 a 36 meses na maioria dos casos, sendo a complicação mais frequente a fibrose pulmonar. ${ }^{1,2} \mathrm{~A}$ taxa de mortalidade associada à sarcoidose varia entre 1-5\%, frequentemente por envolvimento pulmonar, cardíaco e sistema nervoso central. ${ }^{2,7}$

\section{Caso clínico}

Sexo feminino, 60 anos de idade, sem antecedentes pessoais relevantes. Assintomática até Maio de 2009, altura em que iniciou queixas de tosse seca, astenia, associada a febre não quantificada e sudorese noturnas. Em Junho de 2009 por dor abdominal difusa e massa pélvica palpável realizou ecografia abdominal que revelou ascite e massa pélvica, tendo sido enviada a consulta de Ginecologia. Realizada Ressonância magnética (RMN) pélvica que mostrou ascite de pequeno volume na região pélvica, útero miomato-

\begin{abstract}
Sarcoidosis is a systemic granulomatous disease of unknown etiology. Tuberculosis may precede, coexist with sarcoidosis or, less frequently, is an opportunistic disease in patients with sarcoidosis under corticosteroid therapy. We present a 60 -year-old woman who complained of dry cough, fever and night sweats. Subsequently, a pelvic mass suggestive of ovarian neoplasia appeared, and hysterectomy and bilateral adnexectomy were performed. Histological examination revealed circumscribed granulomatous structures, constituted by histiocytes, with no evidence of caseous necrosis. Mycobacterium tuberculosis grew in ascitic fluid culture. Chest CT revealed multiple mediastinal adenomegalies and diffuse interstitial thickening, with a mixed reticular/nodular pattern. She completed 9 months of tuberculosis therapy. Blood test showed elevation of angiotensin converting enzyme. A transthoracic pulmonary biopsy was performed, with histology revealing thickening by fibrosis of interalveolar septa and epithelioid macrophages infiltration with non-caseous granulomas compatible with sarcoidosis.
\end{abstract}

Keywords: pulmonary sarcoidosis; ovarian sarcoidosis; tuberculosis.

so apresentando compressão extrínseca junto ao endométrio, anexos de dimensões aumentadas, múltiplos implantes milimétricos na serosa uterina (figura 1). Por suspeita de neoplasia do ovário foi submetida a histerectomia e anexectomia bilateral. A histologia mostrou estruturas granulomatosas circunscritas e bem definidas nos ovários, tecidos moles peri-tubários, superfície serosa do corpo uterino e em gordura epiploica peritoneal, constituídos por histiócitos de morfologia epitelóide e células gigantes multinucleadas com escassa atividade linfocitária periférica, sem evidência de necrose caseosa (figura 2). No exame cultural do líquido ascítico foi isolado Mycobacterium tuberculosis. Foi enviada a consulta de Medicina Interna para estudo. Ao exame objetivo aquando da primeira consulta, a doente encontrava-se consciente e orientada, eupneica em repouso e sem sinais de dificuldade respiratória. A tensão arterial era de $136 / 82 \mathrm{mmHg}$, com frequência cardíaca de 80bpm. Apirética. Auscultação cardíaca e pulmonar sem alterações. Abdómen sem alterações. Sem edemas periféricos. Realizou tomografia computorizada (TC) do tórax que revelou múltiplas adenomegalias mediastínicas, a dominante com aproximadamente $28 \mathrm{~mm}$ na região infra-carinal e espessamento difuso do interstício, com um padrão misto reticular/ nodular. Perante a presença de granulomas, isolamento no líquido ascítico de Mycobacterium tuberculosis e a presença de múltiplas adenopatias mediastínicas com um padrão reticulo-nodular a nível pulmonar, foi colocada como hipótese diagnóstica tuberculose miliar, tendo a doente cumprido terapêutica com anti-tuberculosos (isoniazida e rifampici- 
na durante 9 meses e etambutol e pirazinamida durante 2 meses). Os exames auxiliares de diagnóstico realizados: VS $35 \mathrm{~mm}$, elevação da enzima de conversão da angiotensina (ECA) 89, 2 U/L, ANAs e ANCAs negativos, fator reumatóide negativo. Pesquisa de micobactérias nas secreções brônquicas e hemoculturas negativas. Ecocardiograma transtorácico sem alterações. Broncofibroscopia com lavado bronco-alveolar (LBA) sem alterações e provas funcionais respiratórias com síndrome ventilatório obstrutivo ligeiro, sem resposta positiva ao broncodilatador inalado.

No entanto, após ter cumprido os noves meses de terapêutica anti-tuberculosa, a doente apresentava dispneia para médios esforços e mantinha queixas de tosse seca. Imagiologicamente persistiam as adenomegalias mediastínicas, espessamento intersticial pulmonar e analiticamente ECA elevada, pelo que foi colocada a hipótese diagnóstica de sarcoidose. Realizada biópsia pulmonar transtorácica guiada imagiologicamente, cujo exame histológico mostrou parênquima pulmonar com septos interalveolares espessados por fibrose e infiltrado de macrófagos epitelióides, por vezes com esboço de granulomas, sem necrose, compatíveis com 0 diagnóstico de sarcoidose.

A doente foi enviada à consulta de Doença do Interstício pulmonar, assumido o diagnóstico de sarcoidose, tendo iniciado corticoterapia $(1 \mathrm{mg} / \mathrm{Kg} / \mathrm{dia})$, que atualmente mantém.

\section{Discussão}

0 diagnóstico de sarcoidose é estabelecido com base em critérios clínicos e radiológicos compatíveis, na presença de granulomas não caseosos. ${ }^{1,2,7,8}$ Apesar de qualquer órgão poder ser afetado, em mais de $90 \%$ dos casos há envolvimento torácico. ${ }^{1}$ A sarcoidose ovárica é uma condição rara, que pode mimetizar neoplasia havendo poucos casos descritos. ${ }^{4,9}$ No caso apresentado, após o tratamento com anti-tuberculosos, a doente mantinha sintomas constitucionais e tosse. Imagiologicamente, a nível pulmonar persistiam adenopatias mediastínicas e infiltrado reticular/nodular e analiticamente apresentava ECA elevada, motivo pelo qual se realizou biópsia transtorácica que foi compatível com sarcoidose pulmonar. Nos ovários foram identificados granulomas não caseosos, compatíveis com sarcoidose ovárica. 0 isolamento de Mycobacterium tuberculosis no líquido ascítico, confirmou a presença de tuberculose peritoneal concomitante.

As semelhanças histológicas entre a sarcoidose e a tuberculose há muito são conhecidas e a associação entre estas duas patologias tem vindo a ser estudada, sendo ainda um tema complexo. ${ }^{3,7} \mathrm{~A}$ tuberculose pode preceder, coexistir com a sarcoidose ou, menos frequentemente, trata-se de uma doença oportunista nos doentes com sarcoidose sob corticoterapia. $^{3,7,10}$

Apresentamos um caso raro de sarcoidose pulmonar e ovárica em doente onde foi isolado Mycobacterium tuberculosis no líquido ascítico, o que acentua o dilema do diagnóstico quando estas duas condições coexistem.

\section{Bibliografia}

1. Iannuzzi MC, Rybicki BA, Teirstein AS. Sarcoidosis. N Engl J Med 2007 Nov 22; 357(21): 2153-65.

2. Nunes H, Bouvry D, Soler P, Valeyre D. Sarcoidosis. Orphanet J Rare Dis 2007 Nov 19; 2: 46.

3. Papaetis GS, Pefanis A, Solomon S, Tsangarakis I, Orphanidou D, Achimastos A. Asymptomatic stage I sarcoidosis complicated by pulmonary tuberculosis: a case report. J Med Case Rep 2008 Jul 7; 2: 226.

4. Wuntakal R, Bharathan R, Rockall A, Jeyarajah A. Interesting case of ovarian sarcoidosis: the value of multidisciplinary team working. World J Surg Oncol 2007 Mar 29; 5: 38.

5. Fité E, Fernández-Figueras MT, Prats R, Vaquero M, Morera J. High prevalence of Mycobacterium tuberculosis DNA in biopsies from sarcoidosis patients from Catalonia, Spain Respiration 2006; 73(1): 20-6.

6. Wong CF, Yew WW, Wong PC, Lee J. A case of concomitant tuberculosis and sarcoidosis with mycobacterial DNA present in the sarcoid lesion. Chest 1998 Aug; 114(2): 626-9.

7. Mise K, Goic-Barisic I, Puizina-Ivic N, Barisic I, Tonkic M, Peric I. A rare case of pulmonary tuberculosis with simultaneous pulmonary and skin sarcoidosis: a case report. Cases $\mathrm{J}$ 2010 Jan 13; 3: 24.

8. Heinle R, Chang C. Diagnostic criteria for sarcoidosis. Autoimmun Rev 2014; 13(4-5): 383-7.

9. Brown JV, Epstein HD, Chang M, Goldstein BH. Sarcoidosis presenting as an intraperitoneal mass. Case Rep Oncol 2010 Jan 12; 3(1): 9-13.

10. Sadikot RT, Doré P, Arnold AG. Sarcoidosis and opportunistic infections. South Med J 2001 Jan; 94(1): 75-7.

Figura 1. RMN pélvica: pequena ascite predominando na região pélvica, mas também observada em topografia sub-capsular hepática. Útero miomatoso apresentando compressão extrínseca junto ao endométrio.

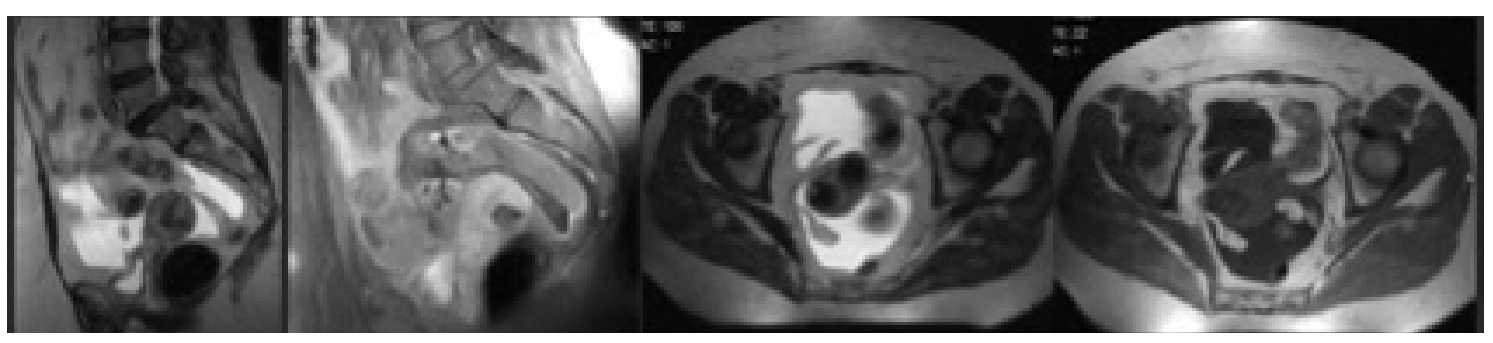

Figura 2. Exame histológico do útero e ovários: granulomatose não necrotizante envolvendo preferencialmente ovário, tecidos moles peri-tubários, serosa uterina e epiplon.

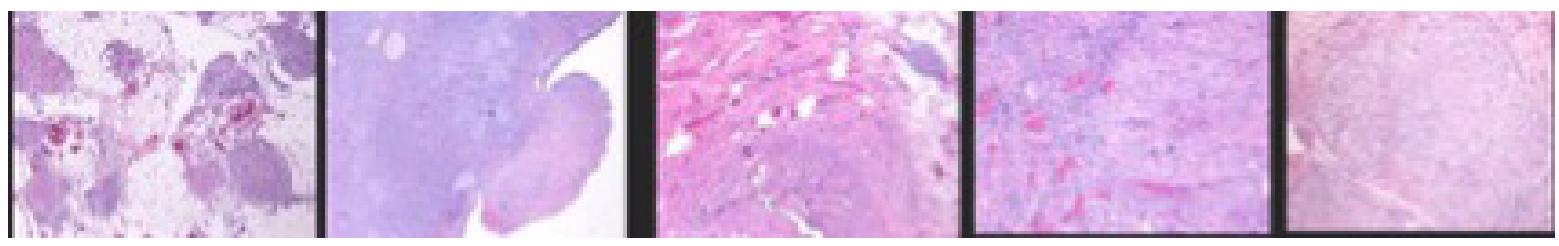

